Dear Author,

Please, note that changes made to the HTML content will be added to the article before publication, but are not reflected in this PDF.

Note also that this file should not be used for submitting corrections. 


\title{
Detection and diversity of aeromonads from treated wastewater and fish inhabiting effluent and downstream waters ${ }^{\text {is }}$
}

\author{
Natalija Topic Popovic ${ }^{a, *}$, Snjezana P. Kazazic ${ }^{b}$, Ivancica Strunjak-Perovic ${ }^{a}$, Josip Barisic ${ }^{a}$, \\ Roberta Sauerborn Klobucar ${ }^{a}$, Slavko Kepec ${ }^{c}$, Rozelinda Coz-Rakovac ${ }^{a}$ \\ a Laboratory for Ichthyopathology-Biological Materials, Rudjer Boskovic Institute, Zagreb, Croatia \\ ${ }^{\mathrm{b}}$ Laboratory for Chemical Kinetics and Atmospheric Chemistry, Rudjer Boskovic Institute, Zagreb, Croatia \\ c Virkom d.o.o., Public Water Supply and Wastewater Services, Virovitica, Croatia
}

\section{A R T I C L E I N F O}

Article history:

Received 22 January 2015

Received in revised form

27 May 2015

Accepted 8 June 2015

Keywords:

WWTP

Aeromonas

MALDI TOF MS

API 20E

Wastewater

\begin{abstract}
A B S T R A C T
A two-season investigation of the wastewater treatment plant (WWTP) effluent, of related waters, sludge and fish across a wide area and 11 stations, with emphasis on Aeromonas spp. was conducted. Aeromonas veronii was the prevailing aeromonad isolated by MALDI TOF MS in the summer period. A rise of Aeromonas hydrophila was observed in summer in raw sewage, treated wastewater and effluent-carrying canal. The ratio of aeromonad species retrieved from fish tissues did not correspond with the water and sludge findings, as in spring in the effluent-carrying canal fish carried Aeromonas salmonicida ssp. salmonicida and Aeromonas bestiarum, while in summer mainly A. veronii and Acinetobacter johnsonii were isolated from fish tissues in the same location. No correlation was established between fecal coliforms/ enterococci and aeromonad occurrence. All retrieved Aeromonas species demonstrated a distinct spectral pattern, with peaks showing unique mass distribution ranging from 4000 to $10,000 \mathrm{Da}$. Hierarchical clustering separated aeromonads of all isolated species and clustered closely related strains together. Resistance was determined towards amoxicillin, and frequently towards sulfamethoxazole and erythromycin. In summer, a high proportion of water and sludge Aeromonas species demonstrated multiple resistance patterns towards five or more antimicrobials. The quinolone resistance of water aeromonads was mostly related to A. veronii. There are potential health concerns regarding aeromonad exposure amongst recreational fishermen who come into contact with fish inhabiting waters downstream from the WWTP, and WWTP workers who are occupationally exposed to wastewaters and their aerosols.
\end{abstract}

(c) 2015 Elsevier Inc. All rights reserved.

\section{Introduction}

Mesophilic aeromonads have been found in almost every aquatic environment, including chlorinated drinking water, raw sewage, groundwater and both polluted and unpolluted streams and rivers (Huddleston et al., 2006). Members of the genus Aeromonas are symbionts of zebrafish, leeches, and dreissenid mussels (Skwor et al., 2014). Aeromonads have been associated with bacterial zoonoses and fish diseases (Austin and Austin, 1999), and recovered from urban sewage and rivers with sewage pollution

${ }^{2}$ This work was supported by the Croatian MSES Grant no. 098-1782739-249, and carried out in accordance with the EC Directive 86/609/EEC for animal experiments. Fish were manipulated by the competent authorized persons (licenced veterinarians) in accordance with the provisions of national legislation and the Institute's Bioethical Committee (No. BEP-274/2-2012). The authors declare no conflict of interest.

* Corresponding author.

E-mail address: ntopic@irb.hr (N. Topic Popovic).

http://dx.doi.org/10.1016/j.ecoenv.2015.06.011

0147-6513/C 2015 Elsevier Inc. All rights reserved.
(Vandewalle et al., 2012). Aeromonas caviae was determined as a dominant species in waters contaminated by sewage and wastewater and pointed out as a potential indicator of sewage pollution (Ramteke et al., 1993). In the sewage treatment ponds aeromonad and coliform distribution is reported to have seasonal cycles, the amplitude of which increases further from the wastewater source (Monfort and Baleux, 1990).

Urban wastewater treatment plants (WWTP) were originally designed to reduce the biological oxygen demand, total suspended solids and nitrogen and phosphorus pollution, while the removal of pathogenic microorganisms has received less attention (Lucas et al., 2014). Although the primary and secondary treatments are able to remove up to $99 \%$ of fecal indicator bacteria (Servais et al., 2007; Lucas et al., 2014), the quality required to use treated wastewaters might be insufficient to achieve the level required for irrigation and recreational activities in the receiving water bodies.

The microbial quality of effluent water is a very important consideration, among other issues because it is reflected in the microbial flora of fish living downstream, which might be fished 
out recreationally and serve as a protein source for humans; however, aeromonads are mostly not considered in such estimations. The main concern in the nowadays customary use of treated wastewaters for fish farming and crop irrigation (El-Shafai et al., 2004; Piveli et al., 2008) is a public health risk. With that in mind, it is worthwhile to consider a broader aspect of the water quality along with fecal contaminants, and include other potentially pathogenic bacteria in this determination, particularly aeromonads. Also, antibiotic sensitivity of environmental Aeromonas spp. needs to be further addressed, since they have not been studied to the same extent as the clinical isolates (Goni-Urriza et al., 2000; Huddleston et al., 2006).

A two-season (spring and summer) microbiological investigation was conducted on representative water, sludge, and fish samples related to a WWTP processing municipal, hospital and sugar plant wastewaters, from 11 stations. The WWTP is a mechanical and chemical-biological facility with activated sludge, encompassing primary and secondary treatments of influents, treating primarily municipal wastewater deriving from a small city of 20,000 residents. Although in some cities wastewater from hospitals is pretreated or biologically treated on-site, on this location it is connected directly to a municipal sewer and treated at the municipal WWTP. The sugar plant is a significant contributor to the wastewater to be treated at the WWTP. The objective of this work was thus to conduct a two-season microbiological investigation of the WWTP effluent and related waters and sludge across a wide area of stations, with special emphasis on diversity Aeromonas species, their impact on health status of fish living downstream, and rapid discrimination with matrix-assisted laser desorption ionization time-of-flight mass spectrometry (MALDI TOF MS) compared with the conventional identification methods.

\section{Materials and methods}

\subsection{Study area}

The study was carried out in spring and summer 2014. The samplings were conducted throughout the treatment process of a
Croatian municipal WWTP, also receiving hospital and sugar plant wastewaters. Sugar plant was active in spring and inactive in summer. The WWTP treatment includes primary and secondary processes, including settling tanks, grit chambers, activated sludge biological process, aeration tanks, secondary tanks for removing the biomass and other suspended particles. The resultant final treated effluent is discharged into a natural water canal. This canal further downstream receives additional communal treated water from a biological treatment plant serving a small suburb, widens to enter a County canal which eventually ends up in Drava river. Therefore, sampling sites for water and sludge are defined as follows: 1: unaffected stream, not related to any industrial nor agricultural waters, considered as a reference site; 2 : inflow of raw municipal wastewaters to the WWTP; 3: inflow of sugar plant wastewaters to the WWTP; 4: treated wastewater leaving the WWTP; 5: canal receiving the effluent; 6: canal after the biological treatment plant; 7: canal entering the County canal; 8: County canal; 9: County canal downstream before the Drava river; 10: WWTP active sludge; 11: sludge from the sugar plant depot (Fig. 1). Water and sludge were collected in glass sterile bottles and polypropylene flasks, refrigerated transported to the lab and immediately analyzed. Samplings were conducted at identical timepoints.

\subsection{Sampling and animals}

This work has been carried out in accordance with the EC Directive 86/609/EEC for animal experiments, and fish were manipulated by the competent authorized persons (licenced veterinarians) in accordance with the provisions of national legislation. Fish were caught by nets and angling at three locations depicted in Fig. 1: unaffected stream (site 1), canal receiving the effluent (site 5), County canal (site 9). In spring, 24 Prussian carp (Carassius gibelio) of both sexes were subjected to examination (mean weight $498.80 \pm 232.04 \mathrm{~g}$, mean length $213.46 \pm 66.94 \mathrm{~mm}$ ). In summer, 19 Prussian carp of both sexes (mean weight $112.94 \pm 65.64 \mathrm{~g}$, mean length $173.78 \pm 30.35 \mathrm{~mm}$ ) were examined. Specimens were randomly sampled, transported live to the laboratory and within few hours from the capture sacrificed by overdose of tricaine
Fig. 1. Sampling sites for raw water, treated water and sludge drawn in the ArcGIS 10.1 program (location: NE Croatia) 1: unaffected stream, not related to any industrial nor agricultural waters, considered as a reference site; 2 : inflow of raw municipal wastewaters to the WWTP; 3 : inflow of sugar plant wastewaters to the WWTP; 4: treated wastewater leaving the WWTP; 5: canal receiving the effluent; 6: canal after the biological treatment plant; 7: canal entering the County canal; 8: County canal; 9: County canal downstream before the river; 10: WWTP active sludge; 11: sludge from the depot. Symbols: BU (biological treatment plant unit), circumpunct (inhabited area). 
methane-sulfonate (MS-222, Sigma, St. Louis, Missouri, USA). Necropsy was performed immediately.

\subsection{Microbiological analyses}

Methods for detection and enumeration of Escherichia coli, coliforms and enterococci from water and sludge were used according to the Detection and enumeration of E. coli and coliform bacteria - Part 1: Membrane filtration method (ISO 9308-1:2000/ Corr.1:2008) and Detection and enumeration of intestinal enterococci - Part 2: Membrane filtration method (ISO 7899$2: 2000)$. E. coli, coliforms and enterococci were also measured from fish tissues (skin and gill scrapings).

All water and sludge samples were inoculated on general purpose media and media for the selective isolation of bacteria (all Oxoid Ltd., England, UK). No selective culture medium for aeromonads was used. Samples of fish gills, kidney and liver were streaked onto Tryptone Soya Agar, MacConkey Agar (Oxoid) and Blood Agar (Certifikat doo, Croatia). Representative colonies were isolated and restreaked on fresh medium until purity was attained. Pure colonies were Gram-stained and subjected to morphological, physiological and biochemical tests. Aeromonads were isolated amongst the culturable heterotrophs recovered on various culture media. Gram-negative fermentative rods, oxydase-producing and gelatine-degrading isolates were presumptively identified as aeromonads. The taxonomic position of the isolates was determined by API 20E panels and Bruker Biotyper MALDI TOF MS.

Antimicrobial susceptibility of the isolated Aeromonas strains was determined with Kirby-Bauer disk diffusion method on Mueller Hinton agar (all Oxoid). The following antimicrobials with respective concentrations were used in the test: oxytetracycline (OTC, $30 \mu \mathrm{g}$ ), amoxicillin (AMC, $30 \mu \mathrm{g}$ ), oxolinic acid (OA, $2 \mu \mathrm{g}$ ), erythromycin (E, $15 \mu \mathrm{g}$ ), sulfamethoxazole (SMX, $50 \mu \mathrm{g}$ ), florfenicol (FFC, $30 \mu \mathrm{g}$ ), norfloxacin (NOR, $10 \mu \mathrm{g}$ ), flumequine (UB, $30 \mu \mathrm{g}$ ). The inoculum was prepared in sterile $5 \mathrm{~mL}$ of $0.85 \%$ Suspension medium (bioMerieux, Marcy l'Etoile, France) and turbidity was adjusted to 0.5 MacFarland's standard. The diameter of the zones of inhibition was read and expressed by referring to the manufacturer's standard table and reported as susceptible (S), intermediate (I) or resistant (R).

The API 20E (bioMerieux, Marcy l'Etoile, France) tests were performed according to the manufacturer's instructions with a few alterations in order to adapt the system to the bacteria of freshwater fish: the incubation time was increased to $48-72 \mathrm{~h}$; the incubation temperature was lowered to $22{ }^{\circ} \mathrm{C}$; only the fermentation of sugars was allowed by sealing the cups with sterile mineral oil in the carbohydrate tests (Topic Popovic et al., 2007). A seven-digit profile was obtained for every tested isolate and identified by the Apiweb software. API 20E ratings were based on three parameters, including the likelihood of a match between the unknown organism's profile and the computer profile, the relative value between the likelihood of the first and the likelihood of the second choices, and the number of tests against the first choice.

Sample preparation for MALDI TOF MS analysis was carried out according to the Bruker protocol using ethanol/formic acid extraction. A single colony was suspended in $300 \mu \mathrm{L}$ distilled water and $900 \mu \mathrm{L}$ absolute ethanol. After centrifugation at $13,000 \mathrm{~g}$ for 2 min, the supernatant was discarded. The pellet was mixed with $10 \mu \mathrm{L} \mathrm{70 \%} \mathrm{formic} \mathrm{acid} \mathrm{and} \mathrm{an} \mathrm{equal} \mathrm{volume} \mathrm{of} \mathrm{acetonitrile} \mathrm{was}$ added. The mixture was centrifuged at $13,000 \mathrm{~g}$ for $2 \mathrm{~min} .1 \mu \mathrm{L}$ of the supernatant was spotted onto a steel target plate and air dried at room temperature. Each sample was overlaid with $1 \mu \mathrm{L}$ of MALDI matrix (a saturated solution of $\alpha$-cyano-4-hydroxycinnamic acid in 50\% acetonitrile and $2.5 \%$ trifluoroacetic acid) and air dried at room temperature.

Mass spectra were automatically generated using microflex LT MALDI TOF mass spectrometer (Bruker Daltonics, Bremen, Germany) operated in the linear positive mode within a mass range of 2000-20,000 Da, according to the manufacturer's instructions. The instrument was calibrated using a Bruker bacterial test standard. Recorded mass spectra were processed with the MALDI Biotyper 3.0 software package (Bruker Daltonics, Bremen, Germany), using standard settings. The MALDI Biotyper output is a log score value in the range $0-3.0$ representing the probability of correct identification of the isolate, computed by comparison of the peak list for an unknown isolate with the reference spectrum in the database. Identification criteria used were as follows: a score of 2.300 to 3.000 indicated highly probable species level identification, a score of 2.000 to 2.299 indicated secure genus identification with probable species identification, a score 1.700 to 1.999 indicated probable identification to the genus level, and a score of $<1.700$ was considered unreliable. The dendrogram was created by MALDI Biotyper MSP creation standard method (Bruker Daltonics) where distance values were relative and always normalized to a maximum value of 1000 .

\section{Results}

\subsection{Bacterial species identified}

In spring, E. coli was identified in all the locations from water and sludge. Fecal coliforms were higher in the reference stream when compared to the canal receiving the effluent and downstream. Fecal coliforms and intestinal enterococci were more abundant in summer (Table 1). From fish tissues (skin and gill scrapings), fecal coliforms and E. coli were absent, while only in fish from the effluent-receiving canal enterococci were identified.

Mainly Gram-negative bacteria were recovered in both seasons from fish, water and sludge. The majority of fish isolates were form gills, and most of the readings indicated to aeromonads. In spring, MALDI TOF MS identified 54.28\% aeromonads from overall fish isolates, while API 20E identified 68.57\%. In summer, the proportion of aeromonads was lower in fish tissues, as MALDI TOF MS

Table 1

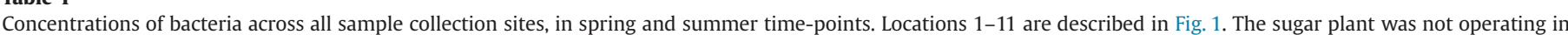

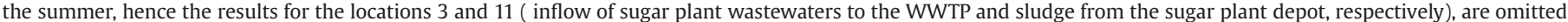
and listed as (-).

\begin{tabular}{|c|c|c|c|c|c|c|c|c|c|c|c|}
\hline Spring & 1 & 2 & 3 & 4 & 5 & 6 & 7 & 8 & 9 & 10 & $11(\mathrm{CFU} / \mathrm{g})$ \\
\hline Fecal coliforms (CFU/100 mL) & $3.2 \times 10^{2}$ & $2 \times 10^{6}$ & $1.3 \times 10^{3}$ & $3 \times 10^{2}$ & 39 & $1 \times 10^{2}$ & 6 & 26 & 40 & $3 \times 10^{5}$ & $6.4 \times 10^{6}$ \\
\hline Intestinal enterococci (CFU/100 mL) & 92 & $1.4 \times 10^{6}$ & $1.3 \times 10^{4}$ & $8 \times 10^{2}$ & $1.4 \times 10^{2}$ & 31 & $4 \times 10^{3}$ & 52 & 40 & $4.3 \times 10^{5}$ & $2 \times 10^{7}$ \\
\hline E. coli (presence/absence) & + & + & + & + & + & + & + & + & + & + & + \\
\hline Summer & 1 & 2 & 3 & 4 & 5 & 6 & 7 & 8 & 9 & 10 & $11(\mathrm{CFU} / \mathrm{g})$ \\
\hline Fecal coliforms (CFU/100 mL) & $1.2 \times 10^{3}$ & $4.4 \times 10^{6}$ & - & $2 \times 10^{3}$ & $8.4 \times 10^{3}$ & $4.2 \times 10^{3}$ & $1.4 \times 10^{2}$ & $2.1 \times 10^{2}$ & $2.8 \times 10^{2}$ & $3.9 \times 10^{5}$ & - \\
\hline Intestinal enterococci (CFU/100 mL) & $1.2 \times 10^{2}$ & $7 \times 10^{5}$ & - & $2 \times 10^{3}$ & $1.6 \times 10^{3}$ & $1.4 \times 10^{3}$ & 0 & $1 \times 10^{2}$ & $4 \times 10^{2}$ & $4.8 \times 10^{5}$ & - \\
\hline E. coli (presence/absence) & + & + & - & + & + & + & + & + & 0 & + & - \\
\hline
\end{tabular}


identified $40.00 \%$ and API 20E $45.00 \%$. Nevertheless, aeromonads were the most represented group of all bacterial genera. Aeromonads were also the most dominant Gram-negative bacteria in overall water and sludge samples (38.64\% by MALDI TOF MS and $50.00 \%$ by API $20 \mathrm{E}$ in spring; $45.45 \%$ by both methods in summer).

Other bacterial species as identified by MALDI TOF MS from fish belonged to various genera: Shewanella spp., Acinetobacter spp., Pseudomonas spp., Rheinheimera spp., Janthinobacterium spp., Citrobacter spp. (spring), and Shewanella spp., Acinetobacter spp., Pseudomonas spp., Klebsiella spp., Enterobacter spp. (summer). From water and sludge samples, MALDI TOF MS identified also: Myroides spp., Providencia spp., Serratia spp., Proteus spp., Lysinibacillus spp., Shewanella spp., Pseudomonas spp. (spring), and Morganella spp., Proteus spp., Alcaligenes spp., Escherichia spp., Providencia spp., Bacillus spp., Pseudomonas spp., Enterobacter spp., Klebsiella spp. (summer). Of all the isolates, only $15.91 \%$ matched to the species in MALDI TOF MS and API 20E systems

\subsection{Presence and differentiation of aeromonads}

The identification match between the two systems was the highest for aeromonads, as they both identified aeromonads to the genus for all isolates and both seasons in $78.78 \%$ of cases, and from these $15.38 \%$ matched by both systems to the species. The proportion of all Aeromonas spp. isolates retrieved from fish, water and sludge by MALDI TOF MS and API 20E is shown in Table 2. Aeromonas veronii was the most frequent aeromonad isolated by MALDI TOF MS, prevailing in summer sampling, but more diversified Aeromonas isolates were determined in spring sampling in all groups. MALDI TOF MS scores ranged from 1.434 to 2.411, where $71.79 \%$ of scores corresponded to score 2.000 to 2.299 , and therefore were termed as Secure genus identification with probable species identification. API 20E results ranged from Unacceptable (where the number of choices proposed were 0 , all the gross frequencies being less than the threshold value) to Excellent identification (\% id $\geq 99.9$ and $\mathrm{T}$ index $\geq 0.75$ ) with only $5.21 \%$ of profiles corresponding to Excellent identification to the genus, and $10.42 \%$ of profiles attributed as Very good identification to the genus.

In spring, the highest frequency of aeromonads was in the County canal (location 8 on the map in Fig. 1.) with both identification systems (99.50\% of all isolates), at the inflow of raw municipal wastewaters to the WWTP, in the treated wastewater leaving the WWTP, and canal receiving the effluent (locations 2, 4, 5 , as $75.00 \%$ of all isolates). In fish captured in spring, there was a significant discrepancy in identification results between MALDI

Table 2

The proportion of all Aeromonas spp. isolates retrieved from fish, water and sludge over all 11 sampling stations, by MALDI TOF MS and API $20 \mathrm{E}$.

\begin{tabular}{|c|c|c|c|c|}
\hline \multirow[b]{2}{*}{ Bacterial isolates (\%) } & \multicolumn{2}{|l|}{ Fish } & \multicolumn{2}{|c|}{ Water and sludge } \\
\hline & \multicolumn{2}{|c|}{ Spring/summer } & \multicolumn{2}{|c|}{ Spring/summer } \\
\hline \multicolumn{5}{|l|}{ MALDI TOF MS } \\
\hline A. veronii (43.47) & 2.89 & 21.73 & 1.45 & 17.39 \\
\hline A. hydrophila (14.49) & - & - & 2.89 & 11.59 \\
\hline A. caviae $(2.89)$ & - & - & 1.45 & 1.45 \\
\hline A. bestiarum (5.79) & 4.35 & - & 1.45 & - \\
\hline A. media (5.79) & 4.35 & - & 1.45 & - \\
\hline A. salmonicida ssp. salmonicida (1.45) & 1.45 & - & - & - \\
\hline A. popoffii (11.59) & 1.45 & - & 10.14 & - \\
\hline Aeromonas sp. (11.59) & - & - & 11.59 & - \\
\hline A. sobria (13.04) & 11.59 & - & 1.45 & - \\
\hline A. ichthiosmia (1.28) & - & 1.45 & - & - \\
\hline \multicolumn{5}{|l|}{ API 20E } \\
\hline A. hydrophila group 1 (44.32) & 11.36 & 4.54 & 21.59 & 6.82 \\
\hline A. hydrophila group 2 (55.68) & 19.32 & 15.91 & 3.41 & 17.05 \\
\hline
\end{tabular}

TOF MS and API 20E for aeromonads: in the unaffected stream (location 1) $28.57 \%$ and $71.42 \%$, respectively; in the canal receiving the effluent (location 5) $33.33 \%$ and $66.67 \%$, respectively; in the County canal downstream before the Drava river (location 9) $50.0 \%$ and $75.0 \%$, respectively. In summer, the highest abundance of aeromonads was identified in the canal entering the County canal (location 7) with both systems (99.00\% of all isolates), but a high percentage $(75.00 \%$ of all isolates) was also retrieved in the unaffected stream (location 1); while in the sludge it was none or negligible. Interestingly, the ratio of aeromonads retrieved from fish tissues did not correspond with the water findings. In the canal receiving the effluent (location 5 ), both systems identified $50.00 \%$ of aeromonads in the water, while in the fish tissues they comprised $29.41 \%$ and $41.18 \%$ as identified with MALDI TOF MS and API 20E, respectively. In the location 9, downstream from the effluent, both systems identified $25.00 \%$ of aeromonads in the water, while in fish tissues they recognized $56.25 \%$ of aeromonads.

The summer and spring aeromonads retrieved from fish and water had a distinct spectral pattern with characteristic fingerprints. The highest intensity MALDI TOF spectral peaks ranged from 4000 to $10,000 \mathrm{Da}$, while the unique mass distribution of each Aeromonas strain identified in spring and summer was showing interspecies similarities at several peaks, particularly between $\mathrm{m} / \mathrm{z} 4800$ and 9000 (not presented). Hierarchical clustering separated aeromonads belonging to the eight different species isolated from water and sludge (Aeromonas popoffii, Aeromonas media, Aeromonas sp., Aeromonas bestiarum, Aeromonas caviae, Aeromonas hydrophila, A. veronii, A. hydrophila ssp. hydrophila) and to six species from fish (Aeromonas encheleia, A. popoffi, A. bestiarum, Aeromonas sobria, A. veronii, A. media) in spring. Aeromonads isolated in summer belonged to three different species isolated from water and sludge ( $A$. caviae, A. hydrophila, $A$. veronii) and two species from fish (A. veronii, Aeromonas ichthiosmia) in summer, with closely related strains clustering together (Fig. 2).

\subsection{Antimicrobial resistance patterns}

Along as towards amoxicillin (AMC), the majority of the spring aeromonads were resistant towards sulfamethoxazole (SMX) and erythromycin (E). A very high proportion of fish aeromonads demonstrated resistance (62.5\%). As much of $50 \%$ of these were also resistant towards SMX. Water aeromonads isolated in spring also demonstrated a high resistance towards oxytetracycline (OTC) and E (11\% for both). In summer, all aeromonads from water and sludge were resistant towards AMC. From these, $28.57 \%$ were also resistant towards five or more antimicrobials, mostly OTC, SMX, E and oxolinic acid (OA). All fish aeromonads in summer were also resistant towards AMC, and for $37.50 \%$ of these that was the only resistance, while the rest of the fish Aeromonas spp. isolates demonstrated resistance towards a single other antimicrobial, mostly E or to a lesser extent, towards SMX.

\section{Discussion}

A risk of pathogens penetrating fish tissues rises if the total counts of heterotrophic aerobic bacteria exceed $10^{4} \mathrm{CFU} / \mathrm{mL}$ of such water, and usually only fecal contamination indicators are used for such estimations (Molleda et al., 2008; Harnisz and Tucholski, 2010). Fecal coliforms and intestinal enterococci in this study were not significantly elevated in water bodies from which fish were captured, except in the summer in the effluent-carrying canal, when they were both slightly increased from allowed $10^{3}$ CFU/100 mL (Table 1). 
a

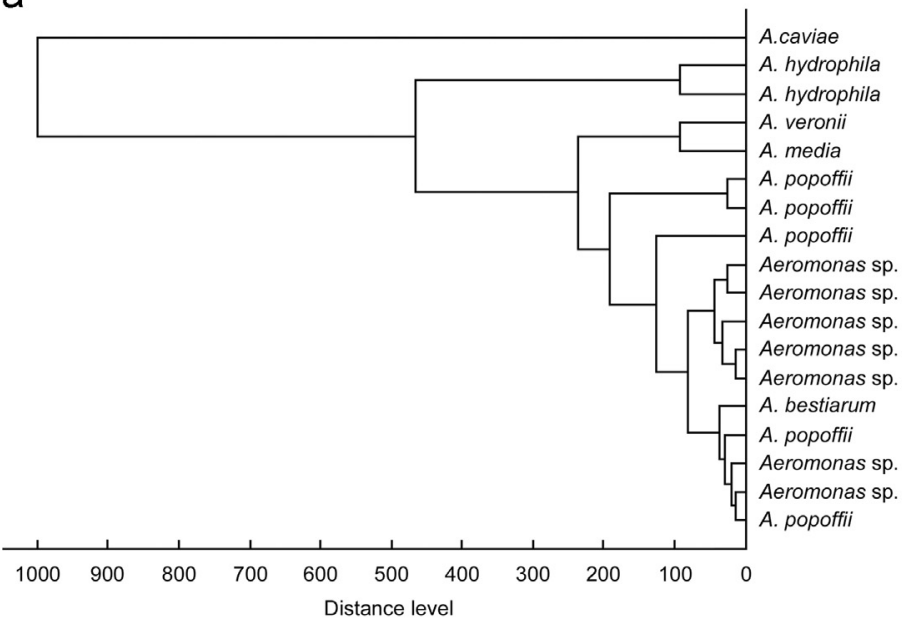

C

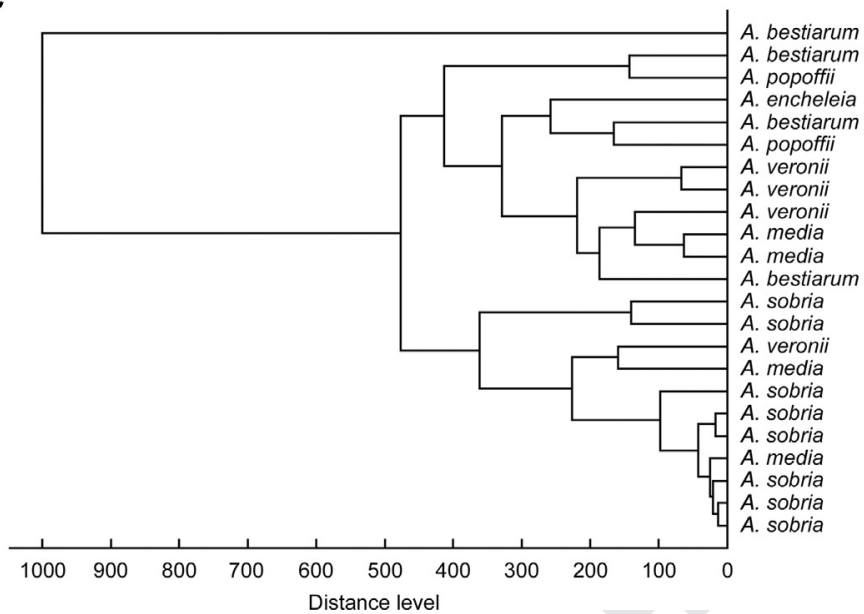

b

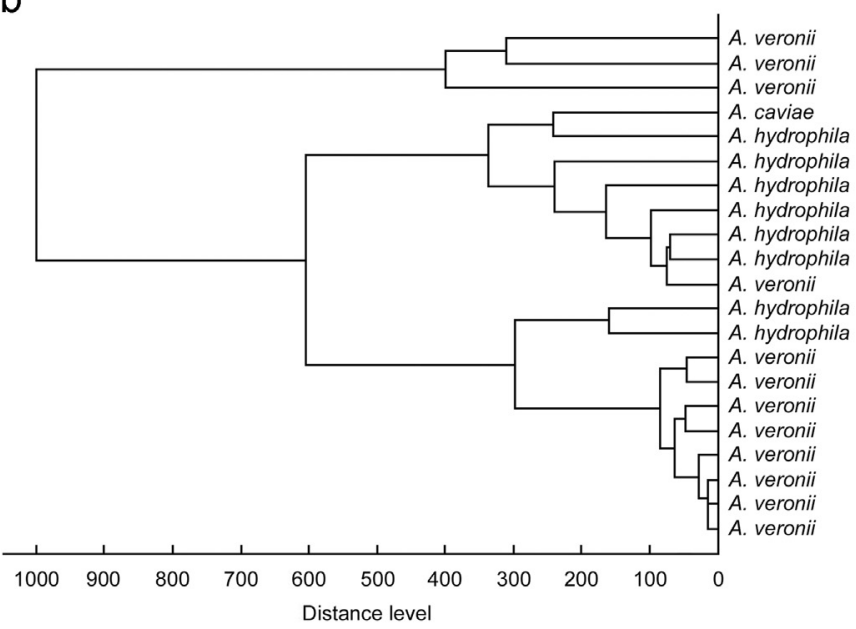

d

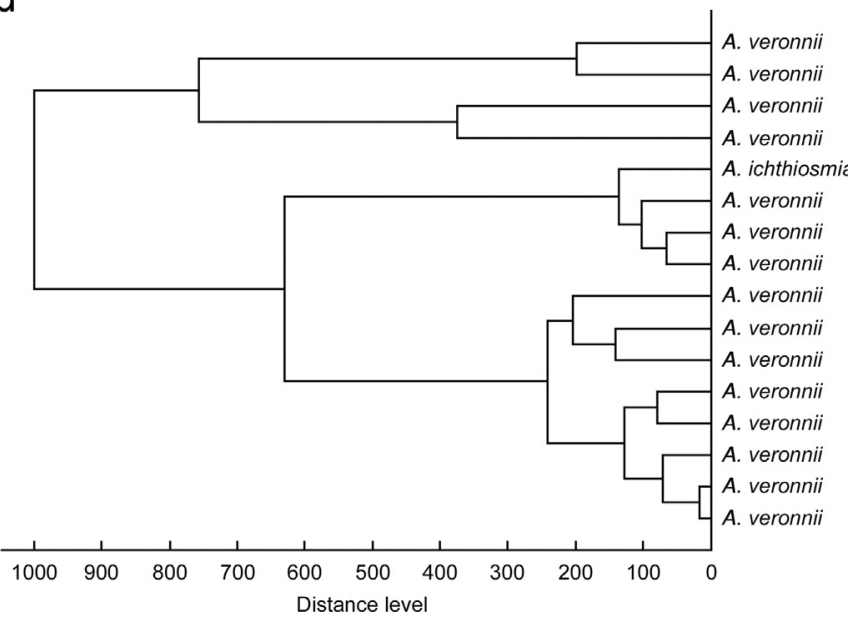

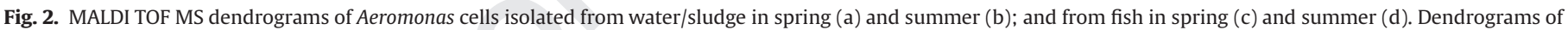

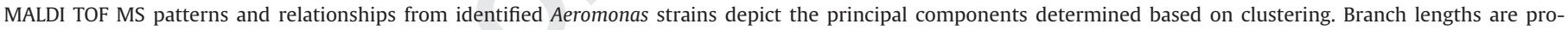
portional to the number of $m / z$ differences between the Aeromonas strains.

\subsection{Occurrence of aeromonads in water and sludge}

The Aeromonas species are frequently isolated from wastewater and effluent of WWTPs, but not many studies have been published to elucidate their dynamics and distribution in those systems (Monfort and Baleux, 1990, 1991; Boussaid et al., 1991; Stecchini and Domenis, 1994; Imziln et al., 1998; Benchokroun et al., 2003; Maalej et al., 2003; Pianetti et al., 2004; Martone-Rocha et al., 2010; Figueira et al., 2011; Vandewalle et al., 2012). In this work, only a slight decrease of aeromonad numbers was noted after the WWTP treatment, but without a total removal after the treatment process, also observed by Martone-Rocha et al. (2010). The same authors report A. caviae as a dominant species in the raw sewage, while Boussaid et al. (1991) list A. caviae and A. hydrophila as dominant in the inlet samples. Our MALDI TOF MS results show $A$. caviae as a relatively rare finding, but $A$. hydrophila prevailed in raw sewage, treated wastewater and effluent-carrying canal in summer. Spring dynamics was more heterogeneous, with equal proportions of $A$. popoffii and A. hydrophila in raw sewage and effluent-carrying canal, while treated wastewater was represented by A. veronii, Aeromonas eurcrenophila, A. media and A. hydrophila alike. A seasonality of aeromonads, coinciding with the raise in the ambient temperature, was previously reported (Janda and Abbott, 2010), supporting our observed rise in A. hydrophila abundance in summer, although a deeper study would be needed to confirm this observation.

In contrast to the work of Figueira et al. (2011), with respect to diversity of Aeromonas species over the sampling stations, the pattern was not distinct in different locations for water and sludge, especially when compared between seasons and operation/nonoperation of the sugar plant. When operating, in spring, the sugar plant contributed with the relatively high bacterial loads, fecal coliforms and enterococci (Table 1), however no link could be established between these isolates and aeromonad occurrence. $E$. coli was a frequent summer finding in vast majority of water and sludge locations, even in the unaffected stream, but with no relation to Aeromonas species occurrence in these sites. The absence of such correlation was also found in the work of Martone-Rocha et al. (2010), suggesting that the aeromonads cannot be estimated by the presence of $E$. coli, used in standard tests for determination of water quality.

\subsection{Occurrence in fish and pathogenicity}

Neither the ratio of aeromonads nor the Aeromonas species retrieved from fish tissues corresponded to water findings, as in spring in the effluent-carrying canal fish carried Aeromonas salmonicida ssp. salmonicida and $A$. bestiarum, while in summer there were mainly A. veronii and Acinetobacter johnsonii in the same location. Although bacterial concentrations in fish tissues are 
reported to increase with the increase of the bacterial load of water, fish have various immunological barriers to protect their tissues from the bacterial agents from the water: external integument with a mucus layer; lymphocytes, granulocytes and macrophages from skin, gills and digestive system; lymphoid organs (Guzman et al., 2004).

A. salmonicida is a causative agent of furunculosis, a devastating fish (mostly salmonid) disease, which was not apparent in our examined specimens. Carrier fish, showing no overt signs of disease, but harboring the pathogen in their tissues, are implicated in horizontal or vertical transmission of furunculosis, and are presumed to provide a reservoir which retains the pathogen in fish populations (Austin and Austin, 1999). This pathogen is reportedly very difficult to isolate from environmental samples other than fish, and often cannot be isolated from water on fish farms even during an epizootic of the disease (Kimura 1970; Austin and Austin, 1999).

Over all sampling stations $A$. veronii was the most frequent aeromonad isolated by MALDI TOF MS in summer, corresponding with the work of Zhou et al. (2013). It is a species considered to be potentially very pathogenic to humans (Martin-Carnahan and Joseph, 2005) with a wide environmental host range. Its involvement in causing disease outbreaks across freshwater fish culture systems coincides with adverse environmental conditions. The major predisposing stress factors include improper handling, temperature shock, low oxygen level, high ammonia and other adverse water quality problems (Plumb and Hanson, 2010, Sreedharan et al., 2013). The variability of overall bacterial and aeromonad species in fish could be attributed to their migration over the water bodies in pursuit of the more favorable feeding locations, which explains a greater bacterial variety in fish from a remote location from the WWTP than in fish captured in the effluent-carrying canal.

\subsection{Methodological differences in strain discrimination}

Although both identification methods identified the same percentage of aeromonads in summer in water and sludge samples, that identification relationship greatly varied in spring, and for fish in both seasons, also with very limited sensitivity in API 20E species distinguishing, attributing all Aeromonas strains to A. hydrophila group 1 or group 2 (Table 2). In contrast, different species of Aeromonas isolates were unambiguously separated by hierarchical clustering by MALDI TOF MS which also gave a very rapid characterization of bacteria at the genus, species and strain level, thus proving its potential for speciating the unknown environmental bacterial isolates (Topic Popovic et al., 2014), although environmental Aeromonas isolates have a wider phenotypic diversity than isolates obtained from clinical samples (Donohue et al., 2007). The genus Aeromonas comprises of over 20 species, and some of them are phenotypically very similar. For example, over $6 \%$ of retrieved aeromonads in this work were identified as $A$. bestiarum by MALDI TOF MS, but were attributed to A. hydrophila by API 20E. This identification disparity can be attributed to close relatedness of the two species, belonging to the same phenogroup, described as the A. hydrophila complex (Martino et al., 2011). MALDI-TOF MS can however provide their good separation at the genospecies level comparable with the phylogenetic tree obtained by gyrB gene sequencing; it categorizes in clusters well differentiated A. bestiarum and A. hydrophila (Benagli et al., 2012). Genus-level accuracy of clinical and environmental Aeromonas isolates identified by MALDI TOF MS in the work of Lamy et al. (2011) was 100\%, while species-level accuracy reached $90.6 \%$, making this system one of the most accurate, rapid and highly reproducible methods for identification of aeromonads (Lamy et al., 2011). MALDI TOF MS spectra, with each strain defined by its mass distribution or a fingerprint spectrum characteristic $(\mathrm{m} / \mathrm{z}$ signature), demonstrated many interspecies similarities, where the spectra of different isolates of the same species clustered together. The relation of the signatures of the Aeromonas strains to each other is graphically depicted (Fig. 2) according to the degrees of association (Donohue et al., 2006; Eddabra et al., 2012). Although designed primarily for clinical specimens, API 20E has found its way in identification of environmental isolates, particularly fish bacterial isolates (Topic Popovic et al., 2007). However, MALDI TOF MS was found a vastly superior alternative to API 20E in identification and classification of aeromonads from water, sludge and fish samples, capable for differentiation of closely related Aeromonas spp.

\subsection{Antibiotic resistance patterns}

Wastewater treatment plants are generally the main receptors of antibiotic resistant bacteria, as well as of soluble chemical contaminants, and are therefore the major reactors in urban areas for antibiotic resistance emergence and development (Novo et al., 2013). Once acquired, antibiotic resistance may be stable in the environment. WWTPs receive large amounts of antibiotics with sewage water from hospitals, livestock manure and private households, where bacteria are exposed to selection pressure. Available data show significantly higher proportion of antibiotic resistant bacteria contained in raw and treated wastewater relative to surface water (Figueira et al., 2011; Bouki et al., 2013). In this work concurrent results for resistant aeromonads were evident only in spring, though in summer multiple resistance towards tested antimicrobials was noted in downstream and unaffected waters as well. Aeromonads isolated from water and sludge showed resistance towards five or more antimicrobials in summer sampling, while a higher proportion of fish aeromonads demonstrated resistance in spring, during the operation of the sugar plant. Resistance in fish aeromonads was not possible to link with a location of sampling. The overall resistance pattern always included AMX, closely related to ampicillin, towards which aeromonads have a natural resistance (Harnisz and Tucholski, 2010). A high resistance towards SMX was also noted, although it is known that alone it is not very active against aeromonads, whilst in combination with trimethoprim, SMX becomes more efficient (Goni-Urriza et al., 2000). The incidence of resistance of environmental Aeromonas spp. samples to SMX in this work was significantly higher than in comparable studies (Imzlin et al., 1996; Kampfer et al., 1999; Huddleston et al., 2006), possibly because our isolates have previously been exposed to antibiotics and chemotherapeutics due to a hospital discharge waters going through the WWTP. Similar explanation is applicable for the resistance towards other antimicrobials, particularly OTC, OA, E and NOR. In contrast to the work of Figueira et al. (2011), the quinolone resistance of water aeromonads was mostly related to the species $A$. veronii, regardless of the type of water.

\subsection{Public health implications}

Our study indicates that aeromonads retrieved from fish, water and sludge related to the WWTP might serve as potential reservoirs of multidrug resistance, irrespective of the season, activity of the sugar plant, or migrational capacity of investigated fish. Such antimicrobial resistance can result in its dissemination to the surrounding ecosystem in view of the adaptability of Aeromonas species to various environments (Huddleston et al., 2006). The resulting environmental reservoir of antimicrobial resistance could serve as a medium for the cycling of antibiotic-resistant aeromonad strains between the environment, the food chain and humans (Rosenberg Goldstein et al., 2014). 
There is a potential health concern regarding aeromonad exposure amongst recreational fishermen who come into contact with fish downstream from the WWTP, and WWTP workers who are occupationally exposed to wastewaters and their aerosols. Aeromonas species have received increased attention due to their association to human diseases and conditions (Skwor et al., 2014). As contact-borne, A. hydrophyila, A. sobria, and A. caviae may cause fish handler disease through skin wound infections and systemic infections, while as food-borne, A. hydrophyila may lead to gastroenteritis, diarrhea and systemic infections (Austin and Austin, 1999; Goni-Urriza et al., 2000; Lehane and Rawlin, 2000; Huddleston et al., 2006; Cabello et al., 2013). Of particular concern is A. veronii as the most frequent aeromonad isolated in summer, having a wide environmental host range, and being pathogenic to humans (Martin-Carnahan and Joseph, 2005). Patients with underlying medical conditions and immunocompromised hosts are more likely to succumb to Aeromonas infections, therefore a thorough history of occupational and recreational exposure is crucial for clinicians in order to provide the appropriate management (Igbinosa et al., 2012).

\section{Conclusions}

Although captured fish demonstrated no signs of disease or impaired health, a good proportion of them carried a bacterial load which significantly pertained to aeromonads, possibly associated with zoonotic diseases, thus potentially endangering WWTP workers and the recreational fishermen downstream from the WWTP. The percentage of aeromonads amongst other bacteria identified by the systems used in this work (MALDI-TOF MS and API 20E) was comparable, although their databases are not comprehensive for environmental isolates. However, the Aeromonas species retrieved by the latter were limited. MALDI-TOF MS proved to be a powerful, low-cost, rapid proteomic tool in aeromonad identification, for which it is surely going to dominate over phenotypic analyses and traditional techniques. API 20E profile should only be used as a guide for environmental aeromonads because of a high rate of misidentifications, even if given at a high confidence level. The antimicrobial resistance patterns across seasons and locations were generally a function of the respective Aeromonas species (A. veronii as quinolone resistant). A very high proportion of fish aeromonads demonstrated resistance, and a notable percentage of these exhibited a multiple resistance pattern. There is a need for increased awareness of the potential passage of antimicrobial resistant determinants to the resistomes of fish and human pathogens. In this regard, negative effects of antimicrobial use on the environment, fish and human health should be elucidated, whilst more WWTPs should be involved in these complex studies.

\section{Acknowledgments}

This work was supported by the Croatian MSES Grant no. 0981782739-249. The authors declare no conflict of interest.

\section{References}

4 Austin, B., Austin, D., 1999. Bacterial fish pathogens: disease in farmed and wild fish. In: Aquaculture and Fisheries. Springer-Praxis, 455

Benagli, C., Demarta, A., Caminada, A.P., Ziegler, D., Petrini, O., Tonolla, M., 2012. A rapid MALDI-TOF MS identification database at genospecific level for clinical and environmental Aeromonas strains. PLoS One 7 (10), 1-6.

Benchokroun, S., Imziln, B., Hassani, L., 2003. Solar inactivation of mesophilic Aeromonas by exogenous photooxidation in high-rate algal pond treating wastewater. J. Appl. Microbiol. 94, 531-538.

Bouki, C., Venieri, D., Diamadopoulos, E., 2013. Detection and fate of antibiotic resistant bacteria in wastewater treatment plants: a review. Ecotoxicol. Environ. Saf. 91, 1-9.

Boussaid, A., Baleux, B., Hassani, L., Lesne, J., 1991. Aeromonas species in stabilization pond in the arid region of Marrakesh, Morocco and relation to fecal pollution and climatic factors. Microb. Ecol. 21 (11), 11-20.

Cabello, F.C., Godfrey, H.P., Tomova, A., Ivanova, L., Dolz, H., Millanao, A., Buschmann, A.H., 2013. Antimicrobial use in aquaculture re-examined: its relevance to antimicrobial resistance and to animal and human health. Environ. Microbiol. 15 (7), 1917-1942.

Donohue, M.J., Smallwood, A.W., Pfaller, S., Rodgers, M., Shoemaker, J.A., 2006. The development of a matrix-assisted laser desorption/ionization-mass spectrometry-based method for the protein fingerprinting and identification of Aeromonas species using whole cells. J. Microbiol. Methods 65, 380-389.

Eddabra, R., Prevost, G., Scheftel, J.M., 2012. Rapid discrimination of environmental Vibrio by matrix-assisted laser desorption ionization time-of-flight mass spectrometry. Microbiol. Res. 167, 226-230.

El-Shafai, S.A., Gijzen, H.J., Nasr, F.A., El-Gohary, F.A., 2004. Microbial quality of tilapia reared in fecal-contaminated ponds. Environ. Res. 95, 231-238.

Figueira, V., Vaz-Moreira, I., Silva, M., Manaia, C.M., 2011. Diversity and antibiotic resistance of Aeromonas spp. in drinking and waste water treatment plants. Water Res. 45, 5599-5611.

Goni-Urriza, M., Pineau, L., Capdepuy, M., Roques, C., Caumette, P., Quentin, C., 2000. Antimicrobial resistance of mesophilic Aeromonas spp. strains isolated from two European rivers. J. Antimicrob. Chemother. 46, 297-301.

Guzman, M.C., Bistoni, M.A., Tamagnini, L.M., Gonzalez, R.D., 2004. Recovery of Escherichia coli in fresh water fish, Jenynsia multidentata and Bryconamericus iheringi. Water Res. 38, 2368-2374.

Harnisz, M., Tucholski, S., 2010. Microbial quality of common carp and pikeperch fingerlings cultured in a pond fed with treated wastewater. Ecol. Eng. 36, $466-470$.

Huddleston, J.R., Zak, J.C., Jeter, R.M., 2006. Antimicrobial susceptibilities of Aeromonas spp. isolated from environmental sources. Appl. Environ. Microbiol. 72 (11), 7036-7042

Igbinosa, I.H., Igumbor, E.U., Aghdasi, F., Tom, M., Okoh, A.I., 2012. Emerging Aeromonas species infections and their significance in public health. Sci. World J., 1-13 2012, article ID 625023.

Imziln, B., Krovacek, K., Baloda, B.S., Kuhn, I., Rey, C.G., Svenson, S.B., 1998. Characterisation of potential virulence markers in Aeromonas caviae isolated from polluted and unpolluted aquatic environments in Morocco. FEMS Microbiol. Ecol. 27, 153-161.

Janda, J.M., Abbott, S.L., 2010. The genus Aeromonas: taxonomy, pathogenicity, and infection. Clin. Microbiol. Rev. 23, 35-73.

Kampfer, P., Christmann, C., Swings, J., Huys, G., 1999. In vitro susceptibilities of Aeromonas genomic species to 69 antimicrobial agents. Syst. Appl. Microbiol. 22, 662-669.

Kimura, T., 1970. Studies on a bacterial disease of adult Sakuramasu (O. masou) and pink salmon (O. gorbuscha) reared for maturitiy. Sci. Rep. Hokkaido Salmon Hatch. 24, 9-100.

Lamy, B., Kodjo, A., Laurent, F., 2011. Identification of Aeromonas isolates by matrixassisted laser desorption ionization-time of flight mass spectrometry. Diagn. Microbiol. Infect. Dis. 71 (1), 1-5.

Lehane, L., Rawlin, G.T., 2000. Topically acquired bacterial zoonoses from fish: a review. Med. J. Aust. 173 (5), 256-259.

Lucas, F.S., Therial, C., Gonçalves, A., Servais, P., Rocher, V., Mouchel, J.M., 2014. Variation of raw wastewater microbiological quality in dry and wet weather conditions. Environ. Sci. Pollut. Res. 21 (8), 5318-5328.

Maalej, S., Mahjoubi, A., Elazri, C., Dukan, S., 2003. Simultaneous effects of environmental factors on motile Aeromonas dynamics in an urban effluent and in the natural water. Water Res. 37, 2865-2874.

Martin-Carnahan, A., Joseph, S.W., 2005. Order XII. Aeromonadales ord. nov., 2nd edition In: Brenner, D.J., Krieg, N.R., Staley, J.T., Garrity, G.M. (Eds.), Bergey's Manual of Systematic Bacteriology, Vol. 2. Springer, New York, p. 556.

Martino, M.E., Fasolato, L., Montemurro, F., Rosteghin, M., Manfrin, A., Patarnello, T. Novelli, E., Cardazz, B., 2011. Determination of microbial diversity of Aeromonas strains on the basis of multilocus sequence typing, phenotype, and presence of putative virulence gene. Appl. Environ. Microbiol. 77 (14), 4986-5000.

Martone-Rocha, S., Piveli, R.P., Matte, G.R., Boria, M.C., Dropa, M., Morita, M., Peternella, F.A., Matte, M.H., 2010. Dynamics of Aeromonas species isolated from wastewater treatment system. J. Water Health 08.4, 703-711.

Molleda, P., Blanco, I., Ansola, G., de Luis, E., 2008. Removal of wastewater pathogen indicators in a constructed wetland in Leon, Spain. Ecol. Eng. 33, 252-257.

Monfort, P., Baleux, B., 1990. Dynamics of Aeromonas hydrophila, Aeromonas sobria, and Aeromonas caviae in a sewage treatmet pond. Appl. Environ. Microbiol. 56 (7), 1999-2006

Monfort, P., Baleux, B., 1991. Distribution and survival of motile Aeromonas spp. in brackish water receiving sewage treatment effluent. Appl. Environ. Microbiol. 57 (9), 2459-2467.

Novo, A., Andre, S., Viana, P., Nunes, O.C., Manaia, C.M., 2013. Antibiotic resistance, antimicrobial residues and bacterial community composition in urban wastewater. Water Res. 47, 1875-1887.

Pianetti, A., Sabatini, L., Bruscolini, F., Chiaverini, F., Cechetti, G., 2004. Faecal contamination indicators, Salmonella, Vibrio and Aeromonas in water used for the irrigation of agricultural products. Epidemiol. Infect. 132, 231-238.

Piveli, R.P., Gunther, W.M., Matté, G.R., Razzolini, M.T., Cutolo, S.A., Martone-Rocha, 
S., Peternella, F.A., Dória, M.C., Matté, M.H., 2008. Sanitation assessment of wastewater treated by stabilization ponds for potential reuse in agricultural irrigation sanitation assessment. Water. Environ. Res. 80 (3), 205-211.

Plumb, J.A., Hanson, L.H., 2010. Health Maintenance and Principal Microbial Diseases of Cultured Fishes, 3rd ed. Wiley, New York.

Ramteke, P.W., Pathak, S.P., Gautam, A.R., Bhattacherjee, J.W., 1993. Association of Aeromonas caviae with sewage pollution. J. Environ. Sci. Health - Part A Environ. Sci. Eng. 28 (4), 859-870.

Rosenberg Goldstein, R., Micallef, S.A., Gibbs, S.G., George, A., Claye, E., Sapkota, A. Joseph, S.W., Sapkota, A.R., 2014. Detection of vancomycin-resistant enterococci (VRE) at four U.S. wastewater treatment plants that provide effluent for reuse. Sci. Total Environ. 466-467, 404-411.

Servais, P., Garcia-Armisen, T., George, I., Billen, G., 2007. Fecal bacteria in the rivers of the Seine drainage network: source, fate and modeling. Sci. Total Environ. $375,153-167$.

Skwor, T., Shinko, J., Augustyniak, A., Gee, C., Anrdraso, G., 2014. Aeromonas hydrophila and Aeromonas veronii predominate among potentially pathogenic ciprofloxacin- and tetracycline-resistant Aeromonas isolates from Lake Eerie. Appl. Environ. Microbiol. 80 (3), 841-848.

Sreedharan, K., Philip, R., Singh, I.S.B., 2013. Characterization and virulence potential of phenotypically diverse Aeromonas veronii isolates recovered from moribund freshwater ornamental fishes of Kerala, India. Antonie van Leeuwenhoek: Int. J. Gen. Mol. Microbiol. 103 (1), 53-57.

Stecchini, M.L., Domenis, C., 1994. Incidence of Aeromonas species in influent and effluent of urban wastewater purification plants. Lett. Appl. Microbiol. 19, 237-239.

Topic Popovic, N., Coz-Rakovac, R., Strunjak-Perovic, I., 2007. Commercial phenotypic tests (API 20E) in diagnosis of fish bacteria. Vet. Med., 52; , pp. 49-53.

Topic Popovic, N., Sauerborn Klobucar, R., Maguire, I., Strunjak-Perovic, I., Kazazic, P. S., Barisic, J., Jadan, M., Klobucar, G., Coz-Rakovac, R., 2014. High-throughput discrimination of bacteria isolated from Astacus astacus and A. leptodactylus. Knowl. Manag. Aquat. Ecosyst. 1 (413), 12. http://dx.doi.org/10.1051/kmae/ 2014005.

Vandewalle, J.L., Goetz, G.W., Huse, S.M., Morrison, H.G., Sogin, M.L., Hoffmann, R.G. Yan, K., Mclellan, S.L., 2012. Acinteobacter, Aeromonas and Trichococcus populations dominate the microbial community within urban sewer infrastructure. Environ. Microbiol. 14 (9), 2538-2552.

Zhou, Q.L., Wang, Y.J., Xie, J., Ge, X.P., Xi, B.W., Liu, B., 2013. Distribution and virulence gene comparison of Aeromonas strains isolated from diseased fish and water environment. Pol. J. Microbiol. 62 (3), 299-302. 